\title{
OPTIMISATION OF THICKNESS OF FIBRE REINFORCED POLYMER SHEETS FOR STRENGTHENING REINFORCED CONCRETE BEAMS WITH FLEXURAL DEFICIENCY
}

\author{
J. M. Kaura \\ DePartment of Civil EngineEring, AhMAdu Bello University, Zaria, KADUNA State. NIGERIA \\ Email address: jmkaura@abu.edu.ng
}

\begin{abstract}
The use of Fiber Reinforced Polymer (FRP) is becoming a widely accepted solution for repairing and strengthening of deteriorated reinforced concrete members, to restore their load carrying capacities. One of the major concerns in the use of FRP is its cost. This therefore calls for the use of efficient and cost effective design approach. Design efficiency in terms of cost can be achieved through optimisation. In the present paper, Generalized Reduced Gradient (GRG) optimisation technique was employed to optimize the strengthening cost of a simply supported reinforced concrete beam strengthened with Fibre Reinforced Polymer (FRP). Optimum design charts for the considered problem were presented. The results showed that considerable savings in thickness can be achieved using FRP of high modulus of elasticity. For example at very high capacity reduction say $70 \%\left(k_{c}=0.3\right)$, the required FRP thicknesses for FRP with elastic moduli of $25 \mathrm{GPa}, 50 \mathrm{GPa}, 75 \mathrm{GPa}, 100 \mathrm{GPa}, 125 \mathrm{GPa}$ and $150 \mathrm{GPa}$ are respectively equal to $2.5 \mathrm{~mm}, 1.75 \mathrm{~mm}, 0.75 \mathrm{~mm}, 0.6 \mathrm{~mm}, 0.5 \mathrm{~mm}$ and $0.4 \mathrm{~mm}$.
\end{abstract}

Keyword: Beam, concrete, Fibre-Reinforced-Polymer, optimisation, polymer, strengthening

\section{INTRODUCTION}

Fiber reinforced polymer (FRP) laminates are increasingly being applied for the rehabilitation and strengthening of infrastructure in lieu of traditional repair techniques such as steel plates bonding [1].Fibre Reinforced Polymer plates have many advantages over steel plates in this application, and their use can be extended to situations where it would be impossible or impractical to use steel. For example, FRP plates are lighter than steel plates of equivalent strength, which eliminates the need for temporary support for the plates while the adhesive gains strength. Also, since FRP plates used for external bonding are relatively thin, neither the weight of the structure nor its dimensions are significantly increased. These various factors in combination make installation much simpler and quicker than when using steel plates. In addition FRP is corrosive resistant, which makes them ideally suited for quick and effective structural repairs [2].

Externally bonded Carbon Fibre Reinforced Polymer (CFRP), Glass Fibre Reinforced Polymer (GFRP),Basalt Fibre Reinforced Polymer (BFRP) or Aramid Fiber Reinforced Polymer (AFRP) sheets, respectively made of carbon, glass, Basalt or Aramid Fiber in polymer matrix (for example epoxy, polyester) have been widely used for retrofitting of strength deficient reinforced concrete structural members $[3,4,5]$. Despite the high cost of Fibre Reinforced Polymer, it has a number of advantages that make it superior to the other strengthening options such as steel sheets. These include very low weight to volume ratio, immunity to corrosion and near zero coefficient of thermal expansion in fiber direction $[6,7]$. Experimental studies conducted on beams strengthened with externally bonded FRP plates $[8,9,10]$ have shown that this technique is very effective and have indicated that the increases in strength of the retrofitted beams can be as high as three times their original capacity, depending on steel ratio, concrete strength, FRP ratio, FRP mechanical properties, and the pre-existing level of damage of the structural element [5].

The use of FRP was first extended to civil infrastructure applications in 1980's and are increasingly used for strengthening and retrofitting of reinforced concrete structures due to ease of application, cost effectiveness and efficient performance [11]. These strengthening and retrofitting techniques widely utilize externally bonded FRP composites due to unique properties such as strength, light weight, corrosion and chemical resistance [12]. The early application of FRP started as flexural strengthening in reinforced concrete bridge girders and 
as confinement to reinforced concrete columns. Today, wide varieties of structural elements are being strengthened using FRP including beams, slabs, columns, shear walls, domes and trusses. Prior to arrival of FRP, the most popular technique for strengthening reinforced concrete structures was using steel plates. This technique had many shortcomings like heavy weight of the steel plates, corrosion that deteriorates bond between the steel plate and the concrete, and requirement for specialized equipment at site for placement of the steel plates. Therefore, FRP sheets have replaced steel plates in strengthening applications [13]. Plate 1 is a typical process for Fibre Reinforced Polymer strengthening of reinforced concrete beam. In this study, investigation into the optimum thickness requirement of FRP for flexural strengthening of steel reinforced concrete beams was presented. Below are some of the major reasons that cause flexural strength deficiency in reinforced concrete beams $[14,15]$ :

i. Environmental effect on structural behaviour, which include chloride-induced corrosion of conventional reinforcing steel in concrete, freezethaw cycling, and wet-dry cycling (all of which can contribute to cracking and deterioration);

ii. Evolution of design loads, such that structures cannot safely carry loads required by updated versions of design codes;

iii. Evolution of design guidelines from working stress (older methodology, such that structures designed using older procedures are inadequate when evaluated under current guidelines;

iv. Increase of traffic and loads due to more cars and heavier trucks on roads and highways.

The aim of this study is to determine the optimum thickness of Fibre-Reinforced-Polymer sheets for flexural strengthening of reinforced concrete beams. The specific objectives include:

i. Development of the objective function for the flexural safety margin of FRP strengthened reinforced concrete beam.

ii. Implementation of the optimisation of the FRP thickness using Generalised Reduced Gradient Method in Microsoft Excel.

iii. Perform sensitivity analysis with the view to investigate in effects of changing design variables (for example, dead to live load ratio, initial flexural capacity reduction factor, steel reinforcement ratio and FRP elastic modulus) on the optimum FRP thickness.

\section{MATERIALS AND METHODS}

\subsection{Problem Formulation}

Cost optimization of the FRP strengthening of a simply supported reinforced concrete beam that lost part of its flexural strengths due factors like corrosion, was implemented. The cost was expressed in terms of the required FRP thickness in mm in conjunction with the material elastic modulus, dead to live load ratio and steel reinforcement ratio. A simply supported reinforced concrete beam with flexural deficiency, strengthened using Fibre Reinforced Polymer (FRP) was considered in this study. The structural configuration of the beam under investigation is shown in Figure 1.

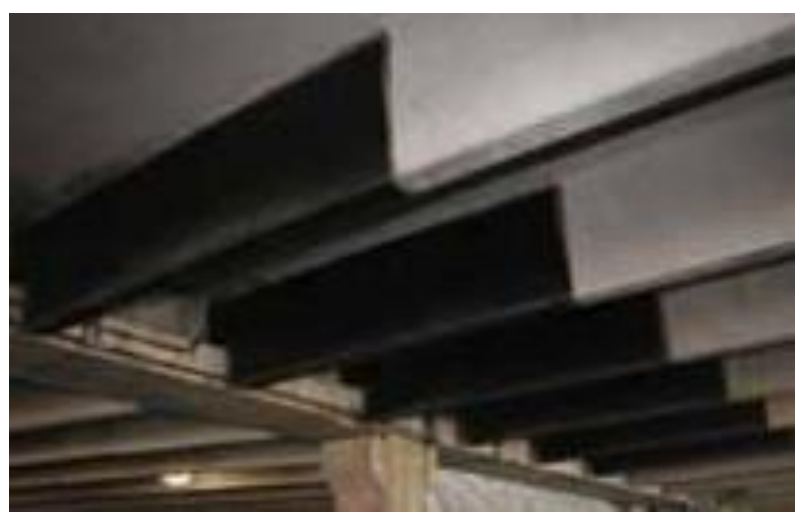

Plate 1: FRP Strengthened reinforced concrete beam [17]
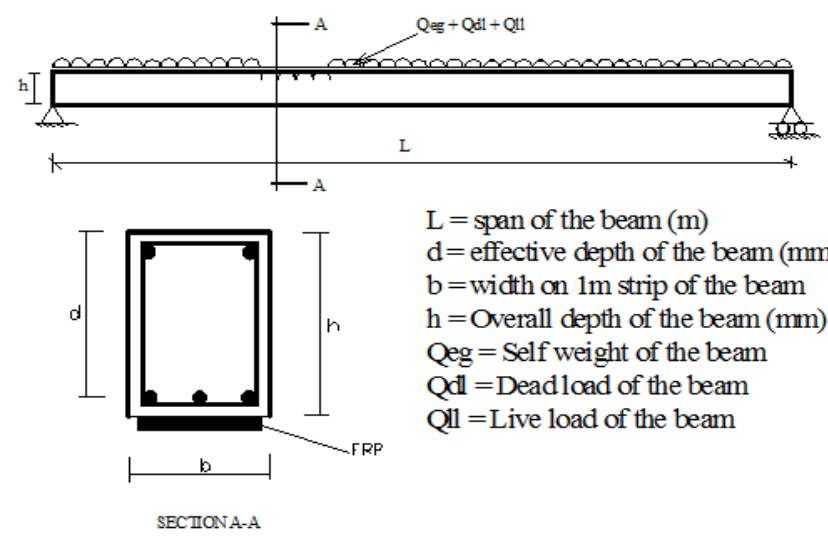

Figure 1: Structural configuration of the beam under investigation

The objective function for the flexural strengthening is given by equation 1 . This is a non-linear constrained optimisation problem

$$
f(x)=M_{R}+M_{F R P}-M_{A}
$$

Where $M_{R}$ is the moment of resistance of the unstrengthened reinforced concrete beam given by equation $2 . \mathrm{M}_{\mathrm{FRP}}$ is the addition moment of resistance provided by the FRP after flexural strengthening, given by equation $3 . M_{A}$ is the applied moment due to the dead and live load, given by equation 4 .

$$
\begin{gathered}
M_{R}=R m_{b} A_{s} f_{y}\left(d-\frac{0.55 A_{s} f_{y}}{b f_{c}}\right) \\
M_{F R P}=\phi_{f r p} E_{f r p} W_{f} t_{f r p} \varepsilon_{f r p}\left(h-\frac{\beta c}{2}\right) \\
M_{A}=0.125\left(m_{e g} q_{e g}+m_{d l} q_{d l}+m_{l l} q_{l l}\right) L^{2}
\end{gathered}
$$

The width and thickness of the FRP must be nonnegative, and the width of the FRP must not exceed the 
overall width of the beam. Based on these conditions, the constraint were defined and given in equation 5 .

$$
w_{\text {frp }} \geq, t_{\text {frp }} \geq 0, w_{\text {frp }} \leq b
$$

Where $m_{b}$ is the flexural resistance factor for the steel reinforced concrete beam, $A_{s}$ is the area of the tension reinforcement in $\mathrm{mm}^{2}$, $\mathrm{f}_{\mathrm{y}}$ is the characteristic strength of the reinforcing steel in $\mathrm{N} / \mathrm{mm}^{2}$, $\mathrm{d}$ is the effective depth of the beam in $\mathrm{mm}, \mathrm{b}$ is the width of the beam in $\mathrm{mm}, \mathrm{f}_{\mathrm{c}}$ is the compressive strength of the concrete in $\mathrm{N} / \mathrm{mm}^{2}, \mathrm{k}_{\mathrm{c}}$ is the flexural capacity reduction factor, representing the lost of flexural capacity due to for example reinforcing steel corrosion, ageing or fire, $\phi_{\text {frp }}$ is the flexural resistance factor of the FRP, $\mathrm{E}_{\text {frp }}$ is the modulus of elasticity of the FRP in N/mm ${ }^{2}, w_{\text {frr }}$ is the width of the FRP in $m m$, $t_{\text {frp }}$ is the thickness of the FRP in $\mathrm{mm}, \mathrm{h}$ is the overall depth of the beam in $\mathrm{mm}, \beta$ and $\mathrm{c}$ are known constants that depend on the compressive strength of the concrete, $\mathrm{m}_{\mathrm{eg}}$ is the modification factor for the selfweight of the beam, $\mathrm{q}_{\mathrm{eg}}$ is the self-weight of the beam in $\mathrm{N} / \mathrm{mm}, \mathrm{m}_{\mathrm{q}}$ is the modification factor for the live and dead load, $\mathrm{q}_{\mathrm{II}}$ is the live load in $\mathrm{N} / \mathrm{mm}, \mathrm{q}_{\mathrm{dl}}$ is the dead load in $\mathrm{N} / \mathrm{mm}$ and $\mathrm{L}$ is the beam span in $\mathrm{mm}$.

The Generalised Reduced Gradient (GRG) method was employed to implement the optimization. GRG is a Microsoft Excel Addinn [16], which is a precise and accurate method for solving non-linear programming problems. The basic concept of GRG method involves linearization of non-linear objective and constraint functions at a local solution with Taylor series expansion. The GRG divide the variable set into two subsets of basic and non-basic variable and the concept of implicit variable elimination was used to express the basic variable by the non-basic variable. The constraints were then eliminated, and the variable space was deduced to only non-basic variables. The method for non-constraints non-linear programming (NLP) problems was then involved to solve the approximated problem and the next optimal solution for the approximated problem should then be found. The processes repeat again until it fulfills the optimal conditions.

Optimisation using the GRG method could be implemented using Solver, which is a Microsoft Excel Add-in. The Excel worksheet that contain the objective function to be optimized, the basic variables that define the objective function as well as the design constraints could be turned into formal design optimisation tools by simply choosing cells corresponding to the design variables, objective function and the suitable constraint functions. In this way, the optimum design could be obtained in a systematic manner.

\subsection{Sensitivity Analysis}

Sensitivity analysis was conducted to investigate the influence of dead-to-live load ratio, steel reinforcement ratio and the modulus of elasticity of the FRP on the optimum thickness of the FRP for the strengthening of reinforced concrete beams with flexural deficiency. The mathematical models for the dead to live load ratio and steel reinforcement ratio are given in equations 6 and 7 respectively.

$$
\begin{aligned}
& \alpha=\frac{q_{e d} q_{d l}}{q_{l l}} \\
& \rho=\frac{A_{s}}{b h}
\end{aligned}
$$

Where $\alpha$ is the dead to live load ratio and $\rho$ is the steel reinforcement ration. $\mathrm{q}_{\mathrm{ed}}, \mathrm{q}_{\mathrm{dl}}, \mathrm{q}_{\mathrm{ll}}, \mathrm{A}_{\mathrm{s}}, \mathrm{b}$ and $\mathrm{h}$ are as defined previously.

\section{RESULTS AND DISCUSSION}

Optimisation of the FRP thickness requirements for the strengthening of simply supported reinforced concrete beam with flexural deficiency was implemented in this study using Generalised Reduced Gradient (GRG) method. Figure 2 is a typical Excel worksheet for the optimisation. For the considered design variables shown on the worksheet, the optimum thickness of FRP ( $t_{\text {frp }}$ ) with modulus of elasticity of $15000 \mathrm{~N} / \mathrm{mm}^{2}$ required to provide predefined flexural capacity is $34.84385 \mathrm{~mm}$.

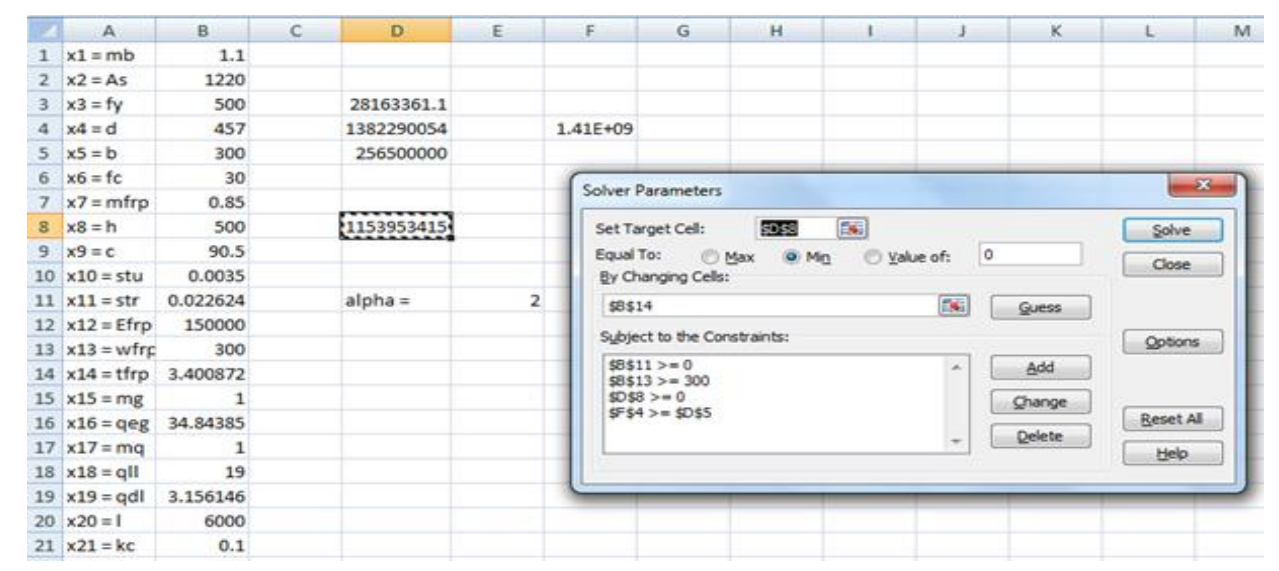

Figure 2: Typical Worksheet for GRG Implementation 
The results of the sensitivity analysis for the influence of dead to live load ratio, steel reinforcement ratio and modulus of elasticity of FRP on the optimum thickness of FRP for various original capacity reductions were presented in Figure 3, 4 and 5 respectively.

The thickness requirements for Fibre Reinforced Polymer (FRP) Laminate for various flexural capacity reduction factors as well as dead to live load ratio were presented in Figure 3. The thicknesses are those that maximized the objective function (equation 1), given the optimum flexural capacity, for various combination of the design variables at the same time satisfying the design constraints. The capacity reduction of the beam is inversely proportional to the flexural deficiency. For instance as can be observed from the plot, when the flexural capacity reduction is $70 \%$ (that is $\mathrm{k}_{\mathrm{c}}=0.3$ ), the FRP thickness requirement to restore the reinforced concrete beam to its full capacity $\left(\mathrm{k}_{\mathrm{c}}=1.0\right)$, for dead to live load ratio of $0.5,1.0,1.5$ and 2.0 were respectively $0.6 \mathrm{~mm}, 1.3 \mathrm{~mm}, 1.9 \mathrm{~mm}$ and $2.6 \mathrm{~mm}$. In the conventional design, the only basic requirement was to prevent limit state violation (that is capacity higher than the demand). This implied that any thickness equal to or above those obtained in Figure3was acceptable. However, the best thickness requirement was the set of the optimized values, notably, because, efficiency and economy are coupled together and there uniformity in the design results.

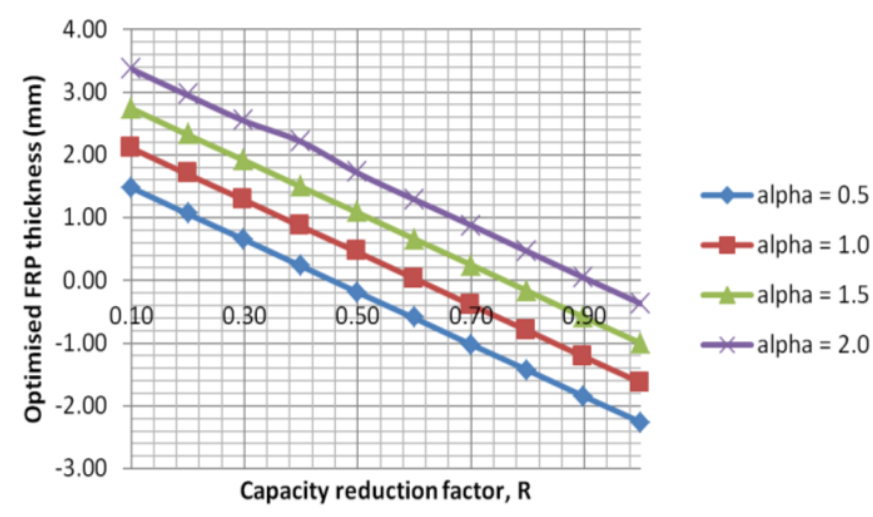

Figure 3: Optimized FRP thickness requirements for various Dead to Live Load Ratio

The relationship between FRP thickness requirement and the flexural capacity reduction of the beam for various steel reinforcement ratios was presented in Figure 4. It is clear from the plot that the initial amount of steel reinforcement play significant role in the strengthening requirement of reinforced concrete beam with flexural deficiency. Five regimes of reinforcement ratios were considered as $0.2,0.4,0.6,0.8$ and 1.0 . When the Flexural deficiency is $90 \%\left(\mathrm{k}_{\mathrm{c}}=0.1\right)$, the thickness of FRP required coincided for all regimes to about $3.5 \mathrm{~mm}$.
As the flexural deficiency reduces the FRP thickness requirement decreased disproportionately. For instance as the flexural capacity reduction increases from $30 \%\left(\mathrm{k}_{c}\right.$ $=0.7)$ to $70 \%\left(\mathrm{k}_{\mathrm{c}}=0.3\right)$ the corresponding increase in the required FRP thickness were75\%, 56\%, 38\%, 25\% and $0 \%$ respectively for steel reinforcement ratios of 1.0 , 0.8. 0.6, 0.4 and 0.2 .

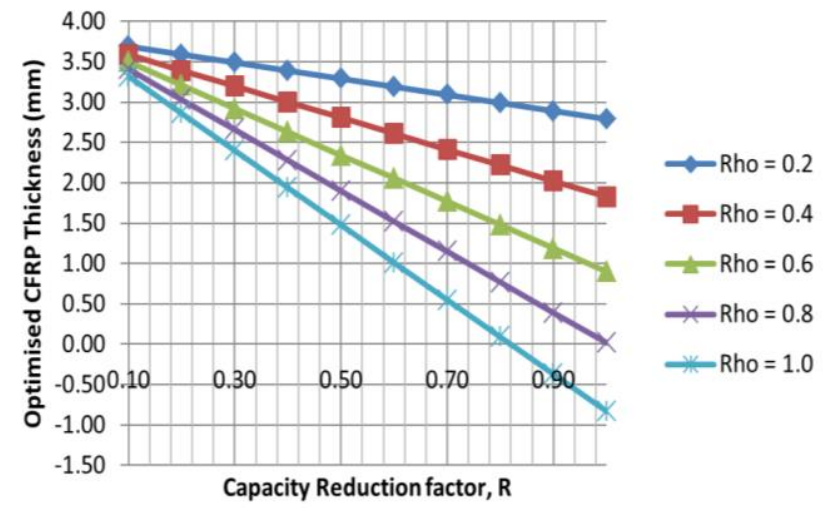

Figure 4: Optimized FRP thickness requirements for various steel reinforcement ratios

The influence of FRP stiffness (Modulus of elasticity) on the values of the optimized FRP thickness requirements was investigated, and the results presented in Figure 5. It is clear from the plot that, at very high capacity reduction say $70 \%\left(\mathrm{k}_{\mathrm{c}}=0.3\right)$, the required FRP thicknesses for FRP with elastic moduli of $25 \mathrm{GPa}, 50 \mathrm{GPa}, 75 \mathrm{GPa}, 100 \mathrm{GPa}$, $125 \mathrm{GPa}$ and $150 \mathrm{GPa}$ were respectively equal to $2.5 \mathrm{~mm}$, $1.75 \mathrm{~mm}, 0.75 \mathrm{~mm}, 0.6 \mathrm{~mm}, 0.5 \mathrm{~mm}$ and $0.4 \mathrm{~mm}$. This implied that at very high capacity reduction, the use of FRP with high elastic modulus such as Carbon Fibre Reinforced Polymer will result to lower optimised FRP thickness. However, the highest cost saving was achieved with the FRP having modulus of elasticity of $75 \mathrm{GPa}$.

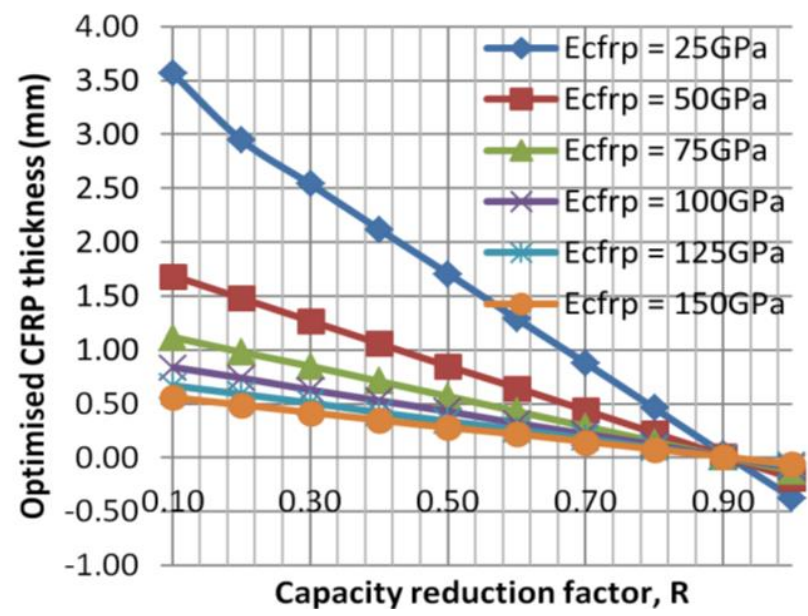

Figure 5: Optimized FRP thickness requirements for various FRP stiffness 


\section{CONCLUSION}

In this research, Generalized Reduced Gradient (GRG) optimisation technique was employed to optimize the FRP thickness requirement for strengthening of a simply supported reinforced concrete beam. Optimum design charts as functions of capacity reduction of reinforced concrete beams were developed. The charts could be used to obtain optimum FRP thickness for various dead to live load ratios, steel reinforcement ratios and modulus of elasticity of the FRP. The results have shown that the magnitude of the optimised FRP thickness required for the strengthening of reinforced concrete beams, subjected to flexural deficiencies depend largely on the modulus of elasticity of the FRP material. The optimised FRP thicknesses for FRP with elastic moduli of $25 \mathrm{GPa}, 50 \mathrm{GPa}, 75 \mathrm{GPa}, 100 \mathrm{GPa}, 125 \mathrm{GPa}$ and $150 \mathrm{GPa}$ were respectively found to be equal to $2.5 \mathrm{~mm}, 1.75 \mathrm{~mm}$, $0.75 \mathrm{~mm}, 0.6 \mathrm{~mm}, 0.5 \mathrm{~mm}$ and $0.4 \mathrm{~mm}$. The lower the thickness of FRP with particular value of elastic modulus, the lower the flexural strengthening cost of reinforced concrete beam.

\section{REFERENCES}

[1] Nikolaos P., Thanasis C. T. 'Reliability of RC Members Strengthened with CFRP Laminates'. J. Struct. Eng. Vol. 121: pp. 1037-1044. 1995.

[2] Rajan S. and Gray M. Application of FRP composites for underwater piles repair. Composites: Part B 38, pp. 751$758,2007$.

[3] Viera, M. M. Santos, A. R. S. Montalverne, A. Bezerra, L. M. Montenegro, L. C. S. Cabral, B. Experimental analysis of reinforced concrete beams strengthened in bending with carbon fiber reinforced polymer. IBRACON Structures and Materials Journal, 9(1), pp. 123-152, 2016.

[4] Dehaghani, H., and Fadace, M. J. 'Reliabilty-based Torsional Design of Reinforced Concrete Beams Strengthened with CFRP Laminate'. JE Transactions A: Basics Vol. 26, No. 10: pp. 1103-1110, 2013.

[5] Naiwu, W. and Bruice, R. E. 'Limit State Design Criteria for FRP Strengthening of RC Bridge Components'. Structural Safety, Vol. 56: pp. 1-8. 2015.

[6] Pannirselvam, N., Nagaradjane, V. and Chandramouli K. 'Strength Behaviour of Fibre Reinforced Polymer
Strengthened Beam'. ARPN Journal of Engineering and Applied Sciences, Vol. 4, No. 9: pp. 34-39. 2009.

[7] Mohamed, H. M., Hamdy, M. A., and Nesreen, M. K. 'Strengthening of Defected Beam-Column Joint Using CFRP. Journal of Advanced Research, Cairo University'. Vol. 5, pp. 67-77. 2014.

[8] Namshik, A., Jaehong, L., Kangsu, L. and Hwa, S. J. An Experimental Study on Flexural Behaviour for a FRP Composite Girder. Construction and Building Materials. Vol. 50: pp 13-21. 2014.

[9] Saadatmanesh, H., and Ehsani, M. R. "RC beams strengthened with GFRP plates. I: Experimental study." Journal of Structural Engineering, 117(11), 34173433.Sato, Y. 1991

[10] Meier, U., and Kaiser, H. "Strengthening of structures with CFRP laminates."Advanced Composite Materials in Civil Engineering Structures - ASCE Specialty Conference, Las Vegas, Nevada, 224-232. 1991.

[11] Burgoyne C and Balafas L. Why id FRP not a Finsancial Success. FRPRCS-8, University of Paltras, Grees, July 1518, 2007.

[12] Bakis, C. E., Ganjehku, A, Kachlakev, D. I., Schupak, m., Balagum, P., Gee, D. J., Karbhari, V. M., Scott, D. W., Ballinger, C. A., and Gentry, T. R. 'Guide for Design and Construction of Externally Bonded FRP System for Strengthening Concrete Structures'. Reported by ACI Committee, Vol. 440.No. 1. 2002.

[13] Teng, J. G., Lam, L., and Chen, J. F. "Shear strengthening of RC beams with FRP composites." Progress in Structural Engineering and Materials, 6(3), 173-184. 2004.

[14] ISIS Educational Module 4 An Introduction to FRP Strengthening of Concrete Structures. Prepared by ISIS Canada.A Canadian Network of Centres of Excellence.www.isis.cana.com. Retrieved Monday, 25th July, 2016. 2004

[15] Attari N., Amziane S. and Chemrouk M. Flexural strengthening of concrete beams using CFRP, GFRP and hybrid FRP sheets. Construction and Building Materials.37 pp 746-757. 2012.

[16] Microsoft Office Professional Plus Version 14.0.7128.5000. 2010.

[17] Tareck A. Optimisation of thickness of Fibre Reinforced Polymer (FRP) sheets for strengthening reinforced concrete beams with flexural deficiency. STRUCTURE magazine, June, 2015.http://www.structuremag.org/wpcontent/uploads/2015/05/C-BuildingBlocks-AlkhrdajiJun151.pdf. retrieved on 15th July, 2016. 2015. 